\title{
Elaboração e Análise Sensorial de Biscoito Tipo Cookie com Castanha-do-Brasil e Óleo de Pequi
}

\author{
Renata K. M. Caetano, Raíza C. Fonseca \& Rosário M. A. Cobucci
}

Este trabalho teve como objetivo a elaboração e a análise sensorial de um biscoito tipo cookie com polpa de castanha-do-Brasil e óleo de pequi. A partir da formulação desenvolvida, foi realizada a análise sensorial quanto à aceitabilidade, utilizando-se uma escala hedônica de nove pontos. A formulação foi bem aceita pelos provadores, obtendo média global 8,0 (gostei muito).

Palavras-chaves: pequi; castanha-do-Brasil; cookie.

This study aimed the development and sensory analysis of a cookie type cookie with pulp-nut Brazil and pequi oil. From the formulation developed sensory analysis was performed as to the acceptability, using a hedonic scale of nine points. The formulation was well accepted by the panelists, obtaining global average 8.0 (liked very).

Keywords: pequi seed oil; Brazil nut; cookie. 


\section{Introdução}

O fruto do pequizeiro é uma drupa com casca verde clara, apresenta endocarpo espinhoso e sua polpa aderida ao caroço é comestível ${ }^{14}$. O pequi é considerado um fruto com um alto valor nutricional, uma vez que possui vitaminas $\mathrm{A}, \mathrm{E}, \mathrm{C}$, ácidos graxos, fósforo, potássio e magnésio. Essas substâncias são importantes ao consumo humano, pois estão ligadas ao bom funcionamento do organismo ${ }^{11}$. Algumas características do fruto pequi são bastante importantes para o mercado in natura, como frutos maiores e de melhor aparência visual, frutos que possuam maiores massas de polpa e de amêndoa ${ }^{16}$. A polpa do pequi fornece cerca de $358 \mathrm{Kcal} / 100$ gramas, sendo correspondentes a cerca de $18 \%$ das necessidades calóricas de um adulto ao se analisar uma dieta de 2.000 $\mathrm{Kcal}^{11}$. O fruto, após atingir o ponto de maturação, tem um curto período de conservação em sua forma in natura, por isso, necessita ser consumido num período curto após a sua colheita. Devido sua produção ser sazonal, gerase a necessidade de técnicas para a conservação destes alimentos para seu consumo posterior ${ }^{10}$.

Gorduras e óleos são constituintes de suma importância na preparação de uma enorme lista de produtos alimentícios, bem como recheios, coberturas, produtos de panificação, sorvetes. Com isso, é de suma importância que se conheçam todas as propriedades físicas e químicas para que se tenha todo controle no processamento e estabelecimento dos padrões para cada uso específico do produto a ser fabricado ${ }^{5}$. Foi feita a caracterização e avaliação do óleo de pequi, Caryocar brasilliense Camb e avaliaram sua estabilidade térmica mostrando um patamar de estabilidade até cerca de $180^{\circ} \mathrm{C}^{4}$. Estudos sobre a influência da exposição do óleo de pequi à luz podem contribuir para uma correta orientação dos produtores e comerciantes, no que se refere ao armazenamento correto dos óleos de pequi, visando à comercialização de óleos com uma boa qualidade e que apresentem, de fato, significativos teores dos componentes funcionais ${ }^{3}$.

A castanheira (Bertholletia excelsa H. \& B.) é uma espécie nativa da Amazônia tendo por habitat terra firme. É uma árvore cujo fruto apresenta alto valor alimentar e com expressão no comércio internacional, constituindose em um dos principais produtos extrativistas da pauta de exportação da Amazônia, principalmente, do estado do Pará ${ }^{18}$. A Castanha-do-Brasil também chamada de "carne vegetal" por ser um alimento rico em vitaminas, proteínas e minerais. A amêndoa da Castanha-doBrasil constitui um alimento bastante apreciado pelos consumidores não só pelo seu sabor como também pelas suas qualidades nutritivas, principalmente, devido à qualidade e quantidade de aminoácidos que apresenta. Diversos estudos mostram que a castanha-do-Brasil apresenta 60 a $70 \%$ de lipídios e de 15 a $20 \%$ de proteína de boa qualidade biológica, além de vitaminas e minerais. Quanto aos minerais, pode ser citada a presença de fósforo, potássio, sódio, magnésio e o selênio. Sendo este último elemento o de maior destaque, por superar em até três vezes o valor da quantidade diária recomendada para um indivíduo adulto ${ }^{15}$. A Castanha-do-Brasil tem tido a pesquisa focada na presença de Selênio, por sua ação antioxidante nos processos metabólicos. Pesquisas associam também como ação do Se a proteção contra ação nociva de metais pesados e na prevenção de doenças crônicas não transmissíveis e no aumento da resistência no sistema imunológico. A recomendação nutricional para um indivíduo adulto é de $55 \mathrm{mg} /$ dia. A ingestão de uma única amêndoa da castanha por dia é o suficiente para suprir a dose nutricional recomendada pelo National Research Council (NRC), dos Estados Unidos. Uma ingestão a partir de $750 \mathrm{mg} /$ dia de Selênio leva a toxidade e a de $11 \mathrm{mg} / \mathrm{dia}$, à deficiência desse elemento ${ }^{15}$. Há várias vantagens com o consumo da Castanha-do-Brasil, contudo é necessário informar sobre a possibilidade de desenvolvimento de alergias se consumidas em grande quantidade, em um período longo. A quantidade recomendada é a ingestão de três castanhas por dia para desfrutar de seus benefícios ${ }^{15}$.

São muitas as formas de classificar um biscoito. Uma classificação muito utilizada é a baseada na forma de modelagem e/ou corte ${ }^{2}$ : laminados e estampados: a massa é laminada e o produto é cortado e estampado por cortadores rotativos ou por prensas. Exemplos: Maria e Cream Cracker; rotativos ou moldados: a massa é prensada nas cavidades de um rolo moldador, com crivos impressos com o desenho desejado, como exemplo temse os recheados; extrusados e cortados por arame: o biscoito é formado por extrusão através de uma trafila (peça que dá o formato desejado produto). O processo pode ser contínuo e o corte feito por guilhotina, por 
fio ou arame, exemplos: rosquinhas, cookies e barras recheadas; depositados ou pingados: são produzidos a partir de uma massa quase líquida e depositados sobre a esteira do forno, em formas ou em bandejas, exemplos: champanha, suspiro e wafer. Qualquer que seja sua origem, o biscoito é um produto consumido internacionalmente por todas as classes sociais. Cada país tem naturalmente sua preferência por determinada classe, que tomadas juntas formam uma extensa seleção de formas, tamanhos, tipos e sabores. Embora não constitua um alimento básico como o pão, os biscoitos são aceitos e consumidos por pessoas de qualquer idade ${ }^{13}$. O termo "cookie" empregado nos Estados Unidos e na Inglaterra, pode ser considerado como sinônimo de biscoito. Estes biscoitos são formulados com a intenção de implementar sua fortificação com fibra e, ou proteína, devido ao forte apelo nutricional existente nos dias atuais para a melhoria da qualidade da dieta ${ }^{8}$. A característica primária de todos os biscoitos é a crocância, devido à atividade de água situando-se entre 0,1 e 0,3 e umidade geralmente entre 2 e $8 \%$. Os cookies são classificados como biscoitos não fermentados, tendo uma formulação bastante simples, contendo poucos ingredientes básicos que são: farinha de trigo, gordura, açúcar, que quando combinados em diferentes proporções e adicionados ao sal e a outros ingredientes específicos, tais como cereais, açucares, gorduras, leite em pó, aditivos, aromas, ovos, frutas, cacau e condimentos resultam em grandes variedades de produtos ${ }^{19}$. Os biscoitos tipo cookies apresentam grande consumo, longa vida de prateleira e boa aceitação, sobretudo entre as crianças ${ }^{8}$.

As indústrias alimentícias têm buscado cada vem mais identificar e atender aos anseios dos consumidores em relação a seus produtos, pois só assim sobreviverão num mercado cada vez mais competitivo. A análise sensorial possui várias aplicações na indústria de alimentos e nas instalações de pesquisas, destacandose análises sensoriais nas etapas de desenvolvimento de novos produtos; análise no controle de qualidade; na seleção de métodos industriais instrumentais que tenham correlação com atributos sensoriais de alimentos. Por meio da análise sensorial, as características ou propriedades de interesse relativas à qualidade sensorial do alimento são identificadas e adequadamente estudadas, com base em metodologias sensoriais de coleta de dados e em métodos estatísticos de avaliação e interpretação dos resultados do estudo sensorial desse alimento ${ }^{12}$. Dessa maneira, as características de qualidade sensorial, tais como sabor, textura e aparência, precisam ser monitoradas desde o momento da percepção e escolha desta qualidade por meio de estudos do consumidor ${ }^{6}$. Existem várias escalas para medir a aceitação, sendo a mais utilizada a escala hedônica. É uma escala facilmente compeendida pelos consumidores, sendo utilizada por muitas empresas que obtiveram resultados válidos e confiavéis ${ }^{12}$.

O Biscoito tipo cookie é um alimento de grande aceitação pela sua praticidade, e aceitabilidade por parte dos consumidores, sobretudo, crianças. Este é um alimento para refeições rápidas e práticas. Visando a inovação e utilização de um novo produto regional no mercado, este trabalho teve como objetivo a elaboração e a avaliação de aceitabilidade de um biscoito tipo cookie de Castanha-do-Brasil e óleo de pequi.

\section{Materiais e Métodos}

\section{MATERAIS}

Foram utilizados os seguintes ingredientes na formulação do biscoito tipo cookie: farinha de trigo; margarina, açúcar mascavo; óleo de pequi, castanhado-Brasil; bicarbonato de sódio e ovos. Os materiais utilizados foram balança semi-analítica; forno semiindustrial; batedeira planetária; silpat- tapete de silicone antiaderente para panificação; bandejas; colheres; tabuleiros; bacias de inox; copos descartáveis de $200 \mathrm{~mL}$.

\section{MÉTODOS}

\section{Processamento}

A formulação foi desenvolvida a partir de testes feitos em laboratório. As formulações foram obtidas de uma receita caseira, a partir desta receita, foram testadas quatro formulações para que se obtivesse a formulação do biscoito proposto. Após cada teste, era realizada degustação pelos alunos do curso de engenharia de alimentos e professores dos cursos de engenharia de alimentos e gastronomia. Os comentários obtidos nortearam as melhorias para a formulação que atendesse ao propósito do trabalho. 
A elaboração dos biscoitos foi dividida em etapas, sendo a pesagem dos ingredientes a primeira. Esta etapa é muito importante para que se obtenha um produto final padronizado. A mistura dos ingredientes ocorreu em duas etapas. Inicialmente, os ingredientes (margarina, açúcares mascavo e refinado e ovo) foram misturados em uma batedeira planetária, em velocidade máxima, até a obtenção de uma massa homogênea. Em seguida, a massa foi colocada em uma vasilha e acrescentaram-se farinha de trigo, bicarbonato, sal, óleo, castanha-do-Brasil e a polpa de pequi, nas formulações que possuem estes ingredientes. Esta mistura foi realizada até a obtenção da consistência desejada.

$\mathrm{Na}$ etapa seguinte, para a modelagem após a massa pronta, esta foi enrolada em filme PVC transparente em forma de cilindro. A próxima etapa foi a de descanso, em que a massa passou por um processo de resfriamento em geladeira por um período de 24 horas. Este processo torna a massa mais endurecida, facilitando a próxima etapa. Após ser retirada da geladeira, essa massa foi cortada em forma de moeda. Após o corte, foi levada ao forno elétrico semi-industrial, a temperatura de $180^{\circ} \mathrm{C}$ por cerca de 15 minutos. Ao finalizar o assamento, os biscoitos foram deixados para resfriar em temperatura ambiente por cerca de 30 minutos. Então, os biscoitos foram acondicionados em sacos plásticos de polipropileno e armazenados até o dia seguinte em local seco e arejado.

\section{Avaliação Sensorial}

O teste foi realizado no laboratório de Análise Sensorial da Pontifícia Universidade Católica de Goiás. A escala hêdonica expressa o gostar ou desgostar, conhecendo- se desta forma o "satus afetivo" dos consumidores com relação ao produto. Dos valores relativos à aceitabilidade, pode-se inferir a preferência, ou seja, as amostras mais aceitas são as preferidas? .

Para estudos de aceitação com adultos, a escala hedônica de 9 pontos é a mais usada. Essa escala possui uma numeração de 1 a 9, em que o provador, ao avaliar a amostra, marca o valor que ele atribui para cada amostra, de acordo com o descrito na ficha do teste de aceitação. A nota $n^{\circ} 1$ corresponde à opção "desgostei muitíssimo"; n 2 "desgostei muito"; no 3 "desgostei moderadamente"; no 4 "desgostei ligeiramente"; $\mathrm{n}^{\mathrm{0}} 5$ "indiferente - não gostei nem desgostei", $\mathrm{n}^{\mathrm{0}} 6$ "gostei ligeiramente", $\mathrm{n}^{\mathrm{o}} 7$ gostei moderadamente", $\mathrm{n}^{\circ} 8$ "gostei muito" e n 9 "gostei muitíssimo".

\section{FAIXA ETÁRIA}

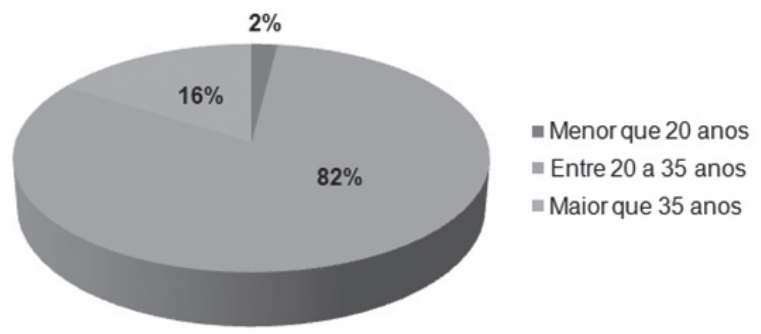

Figura 1. Faixa etária dos provadores. Fonte: Autores, 2015.

Os resultados da escala hedônica podem ser avaliados pela análise da distribuição de frequência dos valores hedônicos, obtidos em cada amostra, por meio de histogramas. Os histogramas tornam possível a visualização da segmentação dos valores hedônicos de cada amostra, revelando o seu nível de aceitação ou rejeição e permitindo a comparação dos desempenhos de duas ou mais amostras. Outra forma de analisar os resultados da escala hedônica é por meio da análise de variância (ANOVA), que considera conjuntamente as avaliações de todos os consumidores e assume que todos apresentam o mesmo comportamento, desconsiderando suas individualidades ${ }^{12}$.

As amostras foram codificadas com três dígitos aleatórios e apresentadas aos provadores a temperatura ambiente. Juntamente à amostra, foi entregue a cada provador na bandeja uma ficha para a avaliação do biscoito e um copo com água. O procedimento se deu em uma sala de avaliação sensorial com cabines individuais, sob luz branca equivalente à luz do dia. O julgamento de aceitação consistiu em cada provador marcar uma das opções na escala hedônica de nove pontos. A ficha apresentada também avaliou a intenção de compra por parte dos provadores em relação ao produto apresentado.

\section{Resultados e Discussão}

\section{PROCESSAMENTO}

Com base na formulação padrão, foram realizados os testes iniciais para obtenção da formulação melhorada selecionada para a análise sensorial. 
No teste 1, utilizou-se apenas óleo de pequi em sua formulação, os resultados obtidos, após as degustações, apontaram que o produto apresentou sabor muito fraco de pequi mas com uma textura adequada de biscoito tipo cookie.

Desta forma, optou-se em realizar mais dois testes: um com acréscimo somente da polpa (teste 2) e outro com a utilização de polpa e óleo (teste 3), pois acreditava-se que a polpa iria realçar o sabor. Como os cookies elaborados nos testes 2 e 3, apresentaram-se com consistência não característica de biscoito tipo cookie (ficaram muito mole e quebradiços), e o sabor permaneceu muito fraco foi necessário realizar o teste 4. Optou-se por aumentar a quantidade do óleo de pequi e retirar a polpa da formulação.

Os resultados obtidos após as degustações da formulação 4 indicaram um biscoito com sabor agradável, além de o produto apresentar textura e consistência adequadas para biscoito tipo cookie. A partir desta formulação, foram produzidos os biscoitos para a análise de aceitação por parte dos provadores.

\section{ANÁLISE SENSORIAL}

A análise sensorial foi conduzida com um grupo de 50 provadores, do sexo masculino e feminino, alunos da Pontifícia Universidade Católica de Goiás. Todos os testes foram realizados com provadores não-treinados, sendo composta por estudantes e funcionários da Pontifícia Universidade Católica de Goiás.

Em relação à idade dos provadores, foi verificado que a maioria possuía idade entre 20 a 35 anos, (82\%) sendo que $2 \%$ tinham idade inferior a 20 anos e $16 \%$ tinham idade superior a 35 anos, como mostrado na Figura 01. A faixa etária entre 20 a 35 anos é a mais usada para aplicar o teste sensorial referente a produtos em geral. Esta faixa recebe maior atenção dos fabricantes, pois além de representar grande porcentagem da população, ela também possui grande potencial de consumo e também por que os hábitos alimentares são formados nessa faixa etária. Já acima de 35 anos, os consumidores tendem a serem mais econômicos devidos a gastos familiares ${ }^{12}$.

Na Figura 2 a seguir, pode-se observar que a maior parte dos provadores que participaram da análise sensorial dos biscoitos tipo cookie era do sexo feminino com $62 \%$ e apenas $38 \%$ do sexo masculino.
SEXO DOS PROVADORES

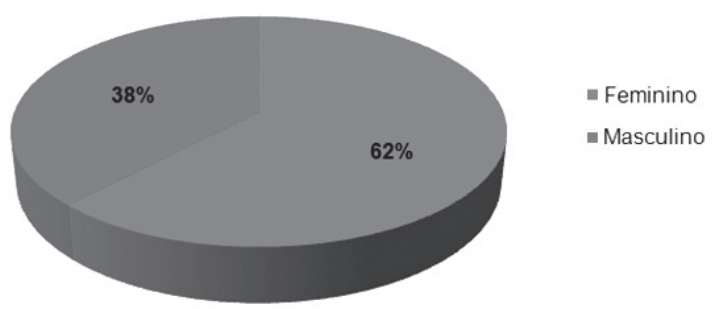

Figura 2. Sexo dos Provadores. Fonte: Autores, 2015.

As diferenças de consumo entre pessoas do sexo masculino e feminino estão cada vez diminuindo, embora as mulheres ainda sejam mostradas como as que adquirem mais bens de consumo e possuem o poder de decisão de compra $^{12,7}$. Conforme pesquisa realizada pela Latin Panel em 2005 e divulgada pela ABRAS (Associação Brasileira de Supermercados) foi constatado que o público feminino determina tendência de mercado, tornando-se, dessa forma, os maiores alvos da pesquisa de marketing.

Após a aplicação do teste de aceitação, os resultados foram tabulados e foi obtida a média da aceitação global e o gráfico de distribuição de frequências das notas. $\mathrm{O}$ biscoito apresentou uma média global igual a 8,0 na escala hedônica de 9 pontos que corresponde à descrição "gostei muito". Os resultados sobre a aceitação global dos biscoitos tipo cookie com Castanha-do-Brasil e óleo de pequi mostraram que em geral o cookie foi bem aceito. De acordo com o gráfico de frequência das notas (Figura 3), aproximadamente metade dos provadores (46\%) "gostaram muitíssimo" do produto.

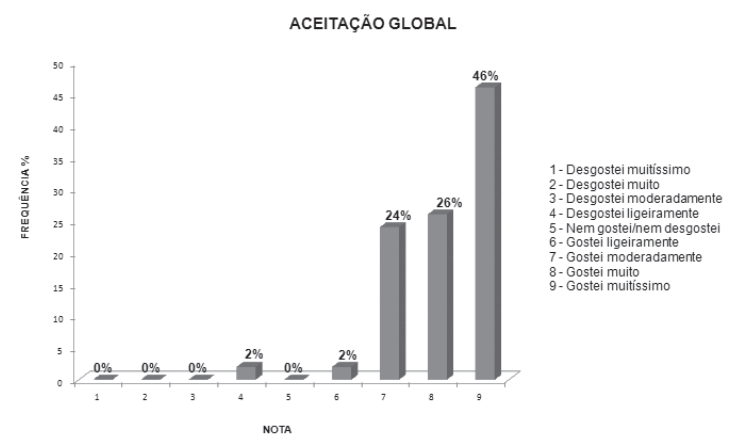

Figura 3. Resultados da análise sensorial do teste de aceitação do biscoito tipo cookie com Castanha-do-Brasil e óleo de pequi. Fonte: Autores, 2015. 
A ficha usada na avaliação sensorial possuía a opção para que os provadores pudessem expressar a sua opinião sobre o produto no campo: "caso queira, dê sua opinião sobre esse produto". Conforme mostrado na Figura 4, verificou-se que a grande maioria dos provadores (70\%) não fez nenhum comentário, e a outra parcela dos provadores (30\%) comentou que o biscoito ficou com uma ótima textura, formato e sabor, contudo um pouco oleoso, este comentário é de suma importância para que o produto possa ser melhorado.

\section{COMENTÁRIOS}

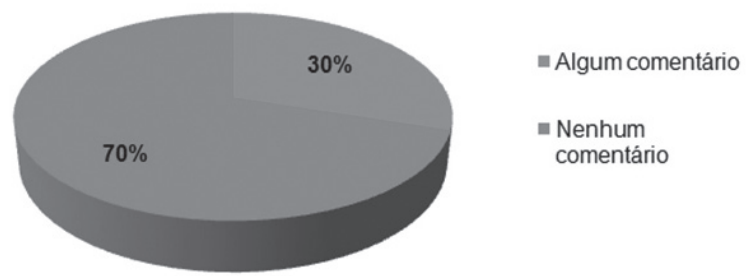

Figura 4. Comentários dos provadores.

Ao solicitar aos provadores "qual seria sua atitude, caso encontrasse esse produto a venda" verificou-se como mostrado na Figura 5, que o biscoito tipo cookie foi bem avaliado no requisito intenção de compra, já que a maioria dos provadores no caso $54 \%$ afirmou que certamente compraria este produto caso encontrasse a venda. Esse critério avaliado faz com que seja comprovada a boa aceitação do produto desenvolvido neste trabalho.

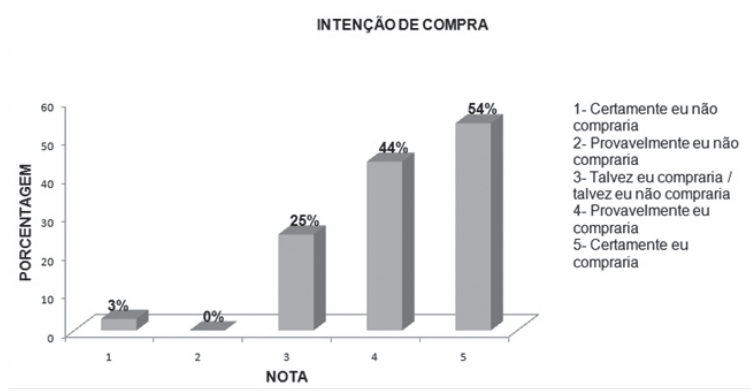

Figura 5. Intenção de compra dos provadores sobra o biscoito tipo cookie de Castanha-do-Brasil e óleo e pequi.

\section{Conclusão}

Para o desenvolvimento de novos produtos, é necessário empenho e dedicação em busca de ingredientes e formulações adequadas, que resultem em produtos de qualidade e que atendam as necessidades e anseios por parte dos consumidores. A avaliação da aceitação de um novo produto por parte do consumidor é um ponto de extrema importância, pode-se utilizar métodos afetivos, os quais medem aceitação ou preferência de um produto, podendo ser de forma individual ou em comparação a outros produtos.

Os resultados obtidos, mediante a realização da análise sensorial do cookie por meio do teste de aceitação escala hedônica, mostrou que o produto foi bem aceito podendo ser uma opção para a utilização de um subproduto derivado da Castanha-do-Brasil e óleo de pequi, sendo que o resultado de intenção de compra vem comprovar este fato já que os provadores certamente comprariam o produto.

A partir dos resultados da análise sensorial, sugerese a realização de trabalhos futuros para caracterização físico-química do produto e determinação do shelf-life do mesmo, bem como demais características importantes para a sua possível comercialização no mercado, visto que foi um produto bem aceito na análise realizada.

\section{Referências}

1. Araújo, W. M. C.; Borgo, L. A.; Botelho, R. B. A.; Montebello, N. D. P. Alquimia dos Alimentos. 2. ed. Brasília: SENAC-DF, 2009. 560p.

2. Azevedo, R. G. Melhoria do forneamento de biscoitos em forno à lenha com processo em batelada. Santa Cruz do Sul, março de 2007. Disponível em: <http://btd.unisc.br/Dissertacoes/ RafaelGuedesdeAzevedo.pdf. Acesso em 24 de set. de 2012.

3. Brasil, R. V.; Cavallieri, A. L. F.; Costa, A. L. M.; Gonçalves, M. A. B. Caracterização Física e química do óleo de pequi exposto a diferentes condições de armazenamento. UFG. Goiânia - Go, 2011.14p. Disponível em:<http://www.ufg.br/conpeex/2011/pibic/ RENATA_V.PDF> Acesso em : 13 de Set. de 2012.

4. Brandão, K. S. R.;Nascimento, U. M.; Silva, F. C.; Souza, A. G.; Conceição, M. M. Avaliação da estabilidade térmica do óleo de pequi. (Caryocar seed oil) .In Congresso Brasileiro De Ánalise Térmica E Calorimetria. 5 ed. Poços de Caldas, 2006. Livro de resumos. Poços de Caldas. ABRATEC, 2006. 172 p

5. Castanheira, L. S. Extração de Polpa e de Óleo de Pequi utilizando Prensa Mecânica. Trabalho de conclusão de Curso (Graduação em Engenharia de Alimentos) PUC - Goiás, Pontifícia Universidade Católica de Goiás, 2005. 64p.

6. Dutcosky, S. D. Análise sensorial de alimentos. 2. ed. Curitiba: Champagnat, 2007. 239 p. 
7. Faria, E. V.; Yotsuyanagi, K. Técnicas de análise sensorial. Campinas: ITAL/LAFISE, 2002.116p.

8. Fasolin, L. H.; Almeida, G. C.; Castanho, P. S. Netto-Oliveira, E. R. Biscoitos produzidos com farinha de banana: avaliações química, física e sensorial. Ciência Tecnologia alimentos, Campinas, v. 27, n. 3, $524-529$ p, 2007. Disponível:<www. scielo.br/pdf/cta/v27n3/a16v27n3.pdf $>$ Acesso em : 24 de Set. de 2012.

9. Ferreira, V. L. P.(Coord.). Análise sensorial: teste discriminativo e afetivo. Campinas - SP. SBCTA, 2000. 127 p.

10. Furtado, G. F.; Porto, A. G.; Zela, S. P.; Silva, F. S. Avaliação físico-química do pequi submetido á secagem em camada delgada.UNEMAT - campus universitário Barra do Bugres, 2008. Disponivel: $<$ http://www.unemat.br/eventos/jornada2008/ resumos_conic/Expandido_00416.pdf> Acesso em : 19 de set. de 2012.

11. Lima, A. (Ed.); Silva, A. M. O. E; Trindade, R. A.; Torres, R. P.; Mancini-Filho, J. Composição química e compostos bioativos presentes na polpa e na amêndoa do pequi (Caryobar brasiliense Camb). Rev. Bras. Frut. Jaboticabal - SP. V 29, n³, 2008. 695 $698 \mathrm{p}$.

12. Minim, V. P. R. Análise sensorial: estudos com consumidores. Viçosa: Editora UFV, 2006. 225 p.

13. Moraes, K. S.; Zavareze, E. R.; Miranda, M. Z.; Salas-Mellado, M. L. M. Avaliação tecnológica de biscoitos tipo cookie com variações nos teores de lipídio e de açúcar. Ciência Tecnologia de Alimentos, Campinas, 30(Supl.1): 233-242, 2010.Disponível:< www.scielo.br/pdf/cta/v30s1/36.pdf $>$ Acesso em : 24 de set. de 2012.

14. Oliveira,M. E. B.;Guerra, N. B.; Maia, A.H.N.; Alves, R. E.; Xavier, D. S.; Matos, M. S. Caracterização física de frutos de pequizeiro nativos da chapada do Araripe - CE. Revista Brasileira de fruticultura. V. 31, n. 4, 2009. Disponível: $<$ http://www.scielo. br/scielo.php?pid=S0100-29452009000400038\&script $=$ sci arttext> Acesso em : 24 de set. de 2012.

15. Pacheco, A. M.; Scussel, V. M. Castanha- do - Brasil: Da Floresta Tropical ao Consumidor. Florianópolis, SC: editograf, 2006. 176 p.

16. Ramos, K. M. C. Variabilidade genética e uso dos frutos de pequi (Caryocarcoriaceumwittm.) na região meio - norte do Brasil. Dissertação ( Programa Regional de Pós- Graduação em Desenvolvimento e Meio Ambiente), UFPI. Teresina, Universidade Federal do Piauí, 2010. 31 p.

17. Ribeiro, A. P. B.; Moura, J. M. L.; Grimald, R.; Gonçalves, L. A. G. Interesterificação química: alternativa para obtenção de gorduras zero trans. Química Nova, Vol. 30, No. 5, 1295-1300, 2007. Disponível:<www.scielo.br/pdf/qn/v30n5/a43v30n5. pdf $>$ Acesso em: 19 de set. de $\mathbf{2 0 1 2}$.

18. Salomão, R. P. Densidade, estrutura e distribuição espacial de castanheira-do-brasil (Bertholletia excelsa H. \& B.) em dois platôs de floresta ombrófila densa na Amazônia setentrional brasileira. Bol. Mus. Para. Emílio Goeldi. Ciências Naturais,
Belém, v. 4, n. 1, p. 11-25, 2009. Disponivel:<www.museugoeldi. br/editora/bn/artigos/.../densidade(salomao).pdf $>$ Acesso em: 24 de set. de 2012.

19. Sarantópoulos, C. I. G. L.; Oliveira, L. M.; Canavesi, E. Requisitos de conservação de alimentos em embalagens flexíveis. Campinas: CETEA/ITAL, 2001. 213 p.

\section{Renata K. M. Caetano ${ }^{*}$, Raíza C. Fonseca ${ }^{2}$ \& Rosário M. A. Cobucci ${ }^{1}$}

${ }^{1}$ Pontifícia Universidade Católica de Goiás, Escola de Engenharia - Engenharia de Alimentos. Avenida Engler, s/n - Jardim Mariliza, BLOCO G - Campus II . CEP: 74885-460, Goiânia, Goiás, Brasil.

${ }^{2}$ Instituto SENAI de Tecnologia em Alimentos e Bebidas,Escola SENAI Vila Canaã - Rua Professor Lázaro Costa n 348 , Vila Canaã, CEP: 74415-420, Goiânia, Goiás, Brasil.

*E-mail: renataklicia@gmail.com 